\title{
Polydimethylsiloxane Shows Strong Protective Effects in Continuous Deep-Frying Operations
}

\author{
Nagao Totani ${ }^{1 *}$, Miho Yawata ${ }^{2}$, and Naoko Yasaki ${ }^{1}$ \\ ${ }^{1}$ Faculty of Nutrition, Kobe-Gakuin University, 518 Arise, Ikawadani-cho, Nishi-ku, Kobe 651-2180, JAPAN \\ ${ }^{2}$ Department of Food and Nutrition, Hakodate Junior College, 52-1 Takaoka-cho, Hakodate 042-0955, JAPAN
}

\begin{abstract}
Polydimethylsiloxane (PDMS) was previously reported to show no protective effect in continuous deep-frying. In this study, we used canola oil with/without added PDMS to deep-fry shredded potato at $180^{\circ} \mathrm{C}$ either continuously or with 10-, 20-, or 30-min intervals between frying sessions for $6 \mathrm{~h}$. In continuous deep-frying in canola oil not containing PDMS, far more oil vapor was generated from the oil and the water in the potato compared to frying with 20- and 30-min intervals between sessions and the oil in the fryer accordingly had a lower polar compound content (PC). The longer the oil was used to deep-fry potato, the more steam was generated from potato. Thus, polar compounds evaporated into the air in the steam, resulting in a low PC value of oil in the fryer. In contrast, both thermal deterioration and oil vaporization were remarkably inhibited in canola oil containing PDMS regardless of the frying pattern, and the PC value of the oil in the fryer increased in proportion to the amount of potato deep-fried. Canola oil with/without added PDMS was heated at $180^{\circ} \mathrm{C}$ for $6 \mathrm{~h}$ to confirm the effect of water released from potato on the oxidation of oil. A large increase in PC was observed in canola oil not containing PDMS when heated without water but this increase was inhibited to some extent when water was supplied continuously. On the other hand, the PC of canola oil containing PDMS was far lower than that of oil not containing PDMS, but the addition of water promoted an increase in PC. In conclusion, we observed superior protective effects of PDMS regardless of the deep-frying pattern employed, but the $\mathrm{PC}$ value nonetheless increased as the amount of food deep-fried increased. In addition, we confirmed that water in potato strongly correlates to $P C$ increase of oil in the fryer.
\end{abstract}

Key words: polydimethylsiloxane, network, continuous deep-frying, oxidation, steam

\section{INTRODUCTION}

Silicone oils are added at ppm concentrations to oil used for industrial purposes to act, for example, as a smoke point enhancer, antifoaming agent, or color inhibitor ${ }^{1-3)}$. Warner et $\left.a l .{ }^{4}\right)$ reported that methyl silicone reduced the altered odor of thermally treated oil.

Polydimethylsiloxane (PDMS) exhibits a far higher protective effect than do natural and other synthetic antioxidants $^{5,6)}$. The protective effect of PDMS in deep-frying operations is reported to be mainly due to PDMS particles dispersed in the oil ${ }^{7)}$. Zeta potential is a measure of the magnitude of the electrostatic or charge repulsion/attraction between particles, and is one of the fundamental parameters known to affect stability. The zeta potential of PDMS droplets suspended in canola oil was very high and thus the negatively charged PDMS droplets should attract nearby low molecular weight compounds. It was suggested that this attraction disturbed the motion of oxygen molecules and prevented their attack against unsaturated fatty acid moiety. This would be the reason why PDMS suppressed the oxidation reaction of oil.

However, there are other interpretations regarding the protective mechanism of PDMS ${ }^{1)}$. Gerde et $a l^{8-10)}$ heated soybean oil statically (without stirring) with added PDMS in a crystallizing dish and found out that the addition of 100 ppb PDMS to soybean oil, enough to form a continuous layer over the surface of the oil, reduced the oxygen concentration when compared to a soybean oil control containing no added PDMS at temperatures ranging from 93 to $180^{\circ} \mathrm{C}$. This suggests an oxygen barrier effect of PDMS, which was also confirmed by our storage experiment using canola oil with added PDMS at $60^{\circ} \mathrm{C}^{11}$. On the other hand, we made a thermal treatment of canola oil covered with a layer of PDMS $\left(0.06 \mu \mathrm{g} / \mathrm{cm}^{2}\right)$ under high agitation $(200 \mathrm{rpm})$

\footnotetext{
*Correspondence to: Nagao Totani, Faculty of Nutrition, Kobe-Gakuin University, 518 Arise, Ikawadani-cho, Nishi-ku, Kobe 651-2180, JAPAN

E-mail: totani@ nutr.kobegakuin.ac.jp

Accepted July 19, 2018 (received for review March 22, 2018)

Journal of Oleo Science ISSN 1345-8957 print / ISSN 1347-3352 online

http://www.jstage.jst.go.jp/browse/jos/ http://mc.manusriptcentral.com/jjocs
} 
mimicking practical deep- frying. The result showed that oxidation proceeded vigorously regardless of the presence or absence of a PDMS layer ${ }^{7)}$. In addition, Freeman et $a{ }^{5}{ }^{5)}$ reported that droplets of excess PDMS will appear in the oil if concentration is greater than ca. 1 ppm. Thus it was proposed that PDMS droplets mainly exhibited the protective effects in the practical deep-frying, while a PDMS layer had the effect in oil heated without disturbance.

Marquez-Ruiz et $a l .{ }^{12-14)}$ and others ${ }^{15)}$ studied the effect of PDMS addition to oils used for continuous and discontinuous frying of potatoes under laboratory conditions. PDMS had a strong positive action in discontinuous frying, and dramatic differences between samples with and without added PDMS were observed. However, PDMS was not effective in simulated continuous frying. Comparison of the results obtained for the discontinuous and continuous frying of potatoes indicated that in continuous frying, the surface of the oil was well protected from the penetration of oxygen by steam generated from the frying potatoes. The authors suggested that the addition of PDMS was unnecessary for continuous frying ${ }^{16-18)}$.

We previously investigated a method for inhibiting the oxidation of oil heated extensively at frying temperatures by blanketing the oil surface with flowing nitrogen and carbon dioxide ${ }^{19)}$, in accordance with a report by Aladedunye ${ }^{20)}$, but observed that carbon dioxide, which is heavier than oxygen, was partially effective with a reasonable amount of flow in protecting the surface of the oil from oxygen penetration. In addition, we investigated why used oil recovered from food manufacturing industries after being used for deep-frying showed low carbonyl values ${ }^{21)}$ and suggested that steam generated from water in deepfried food distilled out decomposition products in oil during the frying process.

In the present paper we again examined the protective effect of PDMS in continuous and discontinuous deep-frying operations and investigated both the volatile oxidation products distilled out from the oil and the characteristics of PDMS dispersed in the oil.

\section{EXPERIMENTAL}

\subsection{Materials}

The canola oil used was a product of J-Oil Mills Ltd. (Tokyo, Japan) and had the following composition: $0.1 \%$ myristic acid, $4.1 \%$ palmitic acid, $0.2 \%$ palmitoleic acid, $1.8 \%$ stearic acid, $64.0 \%$ oleic acid, $18.7 \%$ linoleic acid, $8.8 \% \alpha$-linolenic acid, and $2.3 \%$ other lipids as determined by gas chromatography ${ }^{22)}$. The canola oil did not contain PDMS. All solvents and reagents were purchased from Wako Pure Chemical Industries Ltd. (Osaka, Japan).

\subsection{Chemical properties of the oil}

The polar compound content (PC) of oil was determined using a digital edible oil tester (testo270 ${ }^{\circledR}$, Testo Japan, Yokohama, Japan) by placing the sensor into oil contained in a 15 -mL test tube and heated to $50^{\circ} \mathrm{C}$ for the determination. Good correlation was observed between values obtained by the tester and those obtained by the Japan Oil Chemists' Society standard method for determining the PC of oil. See 2.5 and 3.4.

\subsection{Continuous and discontinuous deep-frying operations in canola oil with and without the addition of PDMS}

The deep-frying conditions were as described by Jorge et $a l^{13)}$. Potato was peeled and shredded (3200 g). Fresh canola oil (3000 g) with or without PDMS added to $2 \mathrm{ppm}^{6)}$ was poured into the tub $(23 \mathrm{~cm} \times 30 \mathrm{~cm} \times 15 \mathrm{~cm}$ deep $)$ of an electric fryer (KCEF-S; Chubo Center, Chiba, Japan). A wire net covered with nonwoven rayon fabric (AS ONE, Tokyo, Japan) was installed over the fryer tub to catch oil vapor released during deep-frying. The surface to volume ratio (SVR) of the oil in the tub was $0.21 \mathrm{~cm}^{-1}$. Canola oil was heated from room temperature to $180^{\circ} \mathrm{C}$ in $20 \mathrm{~min}$, then $100 \mathrm{~g}$ potato was deep-fried for $10 \mathrm{~min}$. This deep-frying operation was repeated with fresh potato 32 consecutive times. After the last batch, the oil was heated another $20 \min (6 \mathrm{~h}$ heating in total) to ensure the oil temperature was at $180^{\circ} \mathrm{C}$. Throughout, the oil in the fryer was not replenished with fresh canola oil. The PC of the residual oil was determined using the testo $270^{\circledR}$. The residual oil, fried potato, and nonwoven fabric were weighed. The fabric was dried using silica gel under reduced pressure at $2 \mathrm{kPa}$. Oil on the nonwoven fabric was extracted with hexane.

In the same manner, $100 \mathrm{~g}$ potato was deep fried for 10 min with 10-min (16 consecutive batches only for canola oil without added PDMS), 20-min (11 consecutive batches) or 30-min (9 consecutive batches) intervals between each frying operation, each for a total operation time of $6 \mathrm{~h}$. The oil was not replenished in any of these deep-frying experiments.

\subsection{Thermal treatment of oil with a continuous supply of water}

Takasago et $a l .^{23,24)}$ reported that water dissolved in oil was closely related to oxidation of the oil, and that oxidation stability of oil increased with decreasing amounts of dissolved water. To confirm if the exclusion of water from potato influences the increase in PC in heated oil, a small amount of water was added continuously for $6 \mathrm{~h}$ to canola oil heated at deep-frying temperatures. A 600-mL, 9 cm diameter beaker containing $300 \mathrm{~g}$ fresh canola oil with or without 2 ppm PDMS was placed in an oil heater and heated from room temperature to $180^{\circ} \mathrm{C}$ in $40 \mathrm{~min}$. Water was supplied to the oil as follows. A ceramic pot $4.5 \mathrm{~cm}$ in diameter containing many small holes was used as the 
water container. All the holes were plugged with tightly rolled Kimwipes (Wipers S-200, Nippon Paper Crecia Co., Ltd. Tokyo, Japan). Water seeped through the paper plugs at a rate of $60 \mathrm{~mL} / \mathrm{h}$. The ceramic pot was gently submerged into the canola oil in the beaker. The PC of the oil was determined using the testo $270^{\circledR}$ every hour during heating. The initial surface to volume ratio was $0.199 \mathrm{~cm}^{-1}$.

\subsection{Correlation between the PC values determined using a testo $270^{\circledR}$ and by column chromatography}

The PC values of many oil samples were measured with a testo2 $70^{\circledR}$. This instrument uses an electrostatic capacitive type sensor and simply and conveniently determines the PC values of thermally treated oils. These values were compared to those obtained by chromatography and compared to find a correlation between the two methods ${ }^{25,26)}$.

\subsection{Viscosity measurement}

The ratio of the viscosity increase is a good indicator of the polymerization of oil under thermal treatment ${ }^{27)}$. The viscosities of the oil samples obtained in 2.3 were determined at $25^{\circ} \mathrm{C}$ using a Viscotesta VT-06 (RION, Tokyo, Japan).

\subsection{Gardner color measurement}

According to the Japan Oil Chemists' Society standard method for determining the color (2.2.1.3), oil color was determined.

\subsection{Statistical analyses}

All experiments were conducted in triplicate. All values for PC are provided as mean \pm SD and were analyzed using one-way analysis of variance with Dunnett's multiple comparison post hoc test. Results were considered significant at $p<0.05$.

\section{RESULTS and DISCUSSION}

3.1 Continuous and discontinuous deep-frying operations with canola oil with and without the addition of PDMS

Table 1 shows the oil volume, SVR, and the highest/ lowest temperature during the deep-frying operation. The SVR of canola oil with or without the addition of PDMS and kept at a temperature of over $160^{\circ} \mathrm{C}$ remained almost unchanged after each $6 \mathrm{~h}$ deep-frying operation. The highest (overrun temperature) and lowest temperature when potato was given to oil, shows the oil temperature range observed during $6 \mathrm{~h}$ deep-frying operation.

The ratio of potato deep-fried/potato raw was similar in the seven deep-frying operations.

Figure 1 shows the weights of oil recovered from the nonwoven fabric used to cover the fryer. Continuous deepfrying in canola oil without added PDMS gave rise to a large

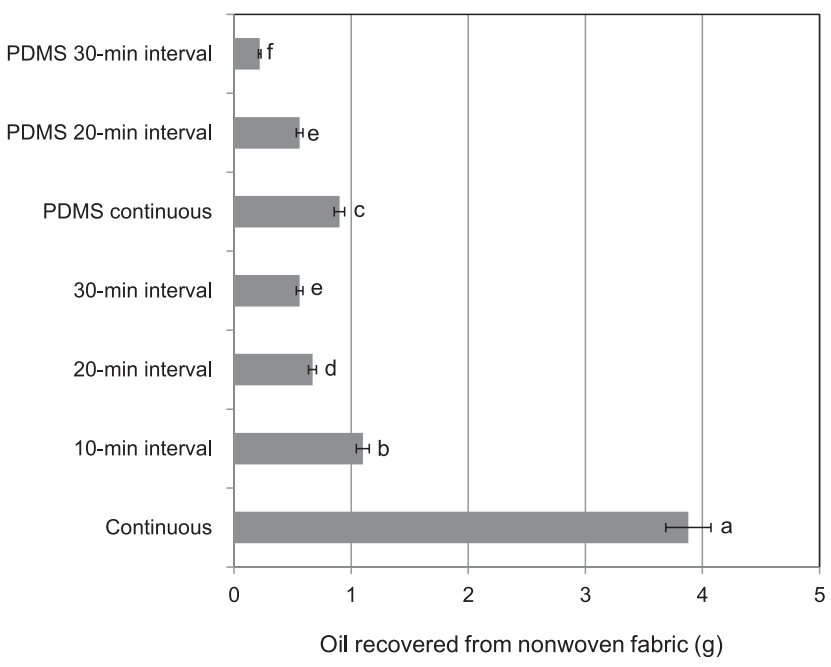

Fig. 1 Oil recovered from nonwoven fabric covering the electric fryer used for deep-frying potatoes at 0 (continuous), 10-, 20-, or 30-min intervals for $6 \mathrm{~h}$ with and without added PDMS. Values are expressed as mean \pm SD. Values with non-common superscript letters differ significantly $(p<0.05)$ by Dunnett's multiple comparison post hoc test.

Table 1 Conditions and results for continuous and discontinuous deep frying operations.

\begin{tabular}{|c|c|c|c|c|c|c|c|}
\hline & Continuous & $\begin{array}{l}\text { 10-min } \\
\text { interval }\end{array}$ & 20-min interval & 30-min interval & $\begin{array}{c}\text { PDMS } \\
\text { continuous }\end{array}$ & $\begin{array}{c}\text { PDMS } \\
\text { 20-min interval }\end{array}$ & $\begin{array}{c}\text { PDMS } \\
\text { 30-min interval }\end{array}$ \\
\hline Oil $0 \mathrm{~h}(\mathrm{~g})$ & 3000 & 3000 & 3000 & 3000 & 3000 & 3000 & 3000 \\
\hline Oil 6 h (g) & $2717 \pm 14^{f}$ & $2824 \pm 10^{d}$ & $2869 \pm 7^{c}$ & $2896 \pm 3^{b}$ & $2756 \pm 14^{e}$ & $2877 \pm 7^{c}$ & $2921 \pm 2^{a}$ \\
\hline $\operatorname{SVR}\left(\mathrm{cm}^{-1}\right) 0 \mathrm{~h}$ & 0.212 & 0.212 & 0.212 & 0.212 & 0.212 & 0.212 & 0.212 \\
\hline $\operatorname{SVR}\left(\mathrm{cm}^{-1}\right) 6 \mathrm{~h}$ & $0.234 \pm 0.001^{\mathrm{a}}$ & $0.225 \pm 0.001^{\mathrm{c}}$ & $0.222 \pm 0.001^{d}$ & $0.220 \pm 0.001^{d}$ & $0.231 \pm 0.001^{b}$ & $0.221 \pm 0.001^{d}$ & $0.218 \pm 0.001^{\mathrm{e}}$ \\
\hline The highest temperature $\left({ }^{\circ} \mathrm{C}\right)$ & 184 & 182 & 183 & 184 & 181 & 183 & 184 \\
\hline The lowest temperature $\left({ }^{\circ} \mathrm{C}\right)$ & 164 & 163 & 164 & 162 & 163 & 164 & 164 \\
\hline Potato (g) & 3200 & 1600 & 1100 & 900 & 3200 & 1100 & 900 \\
\hline
\end{tabular}

PDMS: polydimethylsiloxane, SVR: surface to volume ratio. Values of Oil $6 \mathrm{~h}(\mathrm{~g})$ and SVR $\left(\mathrm{cm}^{-1}\right) 6 \mathrm{~h}$ are expressed as mean \pm SD. Values with non-common superscript letters differ significantly $(p<0.05)$ by Dunnett's multiple comparison post hoc test. 


\section{N. Totani, M. Yawata, and N. Yasaki}

amount of oil vapor whereas the amount of oil vapor generated in discontinuous deep-frying varied according to the amount of potato fried. Interestingly, the addition of PDMS to canola oil resulted in little oil vaporizing in both continuous and discontinuous deep-frying. In addition, the weight of canola oil with added PDMS left-over in fryer was greater than that of the corresponding oil without added PDMS (Table 1). PDMS particles dispersed in oil show a high zeta potential and form a network ${ }^{7)}$ which would greatly hinder oil volatilization. Kusaka et $a l .{ }^{28)}$ also reported that silicone oil disturbed water evaporation in frying oil. Babayan ${ }^{29)}$ patented the process for the addition of methyl and ethyl silicones to oil to increase the smoke point by $8-19^{\circ} \mathrm{C}$, consistent with our present results. Deepfrying plants and outlets using oil with added PDMS do not have oil stains (private communication). Furthermore, we previously reported that PDMS particles reduced the volatilization of low molecular weight compounds in thermally deteriorated canola oil at ambient temperature ${ }^{7)}$, in agreement with the report by Warner et $a l .{ }^{4}$.

As shown in Fig. 2, the PC of canola oil without added PDMS used in discontinuous frying increased significantly regardless of the interval length. In addition, the longer the interval, the higher the PC value, because oxidation products are vigorously distilled out by steam generated when food is deep-fried ${ }^{21)}$. Canola oil containing PDMS showed remarkably inhibited increases in $\mathrm{PC}$, and the longer the interval, the lower the $\mathrm{PC}$ value. Consequently, the increase in $\mathrm{PC}$ with respect to the interval was reversed as com-

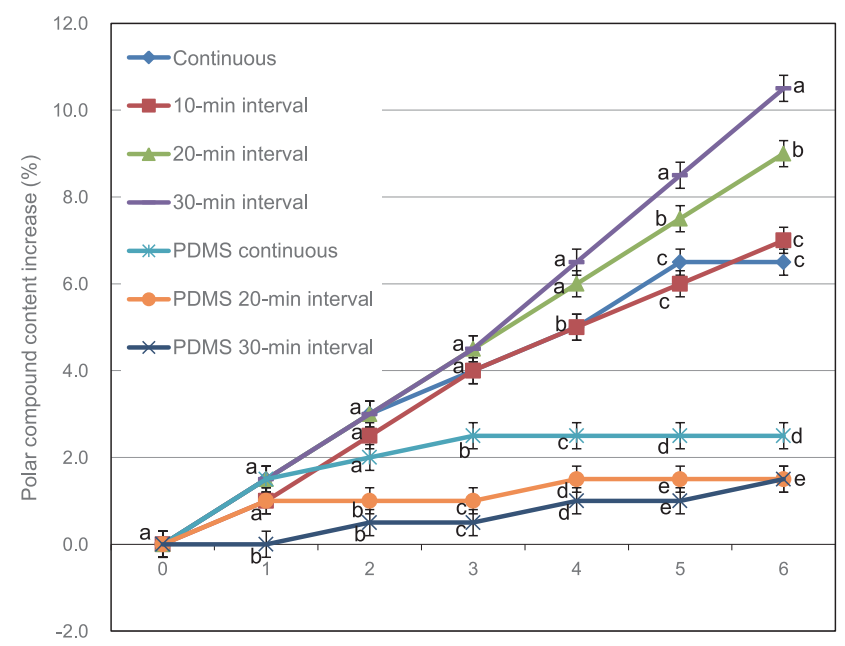

Heating time (h)

Fig. 2 Polar compound content of canola oil with and without added PDMS used for deep-frying potato at 0-(continuous), 10-, 20-, or 30-min intervals for $6 \mathrm{~h}$. Values are expressed as mean \pm SD. Values with non-common superscript letters differ significantly $(p<0.05)$ by Dunnett's multiple comparison post hoc test. pared to canola oil not containing PDMS. In general, increases in heating time and in water contained in food used for hydrolysis increase the PC value while steam generated from food decreases PC value due to steam distillation. In addition, PDMS dispersed in oil drastically inhibits oil volatilization, as described above.

Our previous thermal experiment at $180^{\circ} \mathrm{C}$ for $5 \mathrm{~h}$ using canola oil with and without PDMS, containing $672 \mu \mathrm{g} / \mathrm{g}$ natural tocopherols showed slight decrease of total tocopherols in PDMS-canola oil, whereas very large decreases were observed with pure canola oil, with $92 \%$ of the tocopherols destroyed after $5 \mathrm{~h}$ heating ${ }^{6)}$. Tocopherols are antioxidants that should function independently in eliminating radicals regardless of the presence or absence of PDMS in canola oil, assuming that PDMS does not interfere with tocopherol activity. However, residual total tocopherols were obviously high in PDMS-canola oil. In the oxidation of oil, fatty acid radicals initially generated are attacked by oxygen to form peroxide radicals, then tocopherols react with the radicals, resulting in stable products $^{30)}$. This process involves oxygen consumption; tocopherols decrease with the radical elimination and thermal decomposition. On the other hand, PDMS should neither react with the radicals described above nor consume oxygen. Thus, PDMS inhibited the oxidation of canola oil in a manner ${ }^{6,7)}$ different from the radical elimination of tocopherols and prevented the consumption of tocopherols.

The Gardner color values of canola oil heated for $6 \mathrm{~h}$ are shown in Fig. 3. The color of all heated oil samples not containing PDMS deteriorated markedly and there was no statistical difference among the samples, suggesting that the color deterioration of oil not containing PDMS was

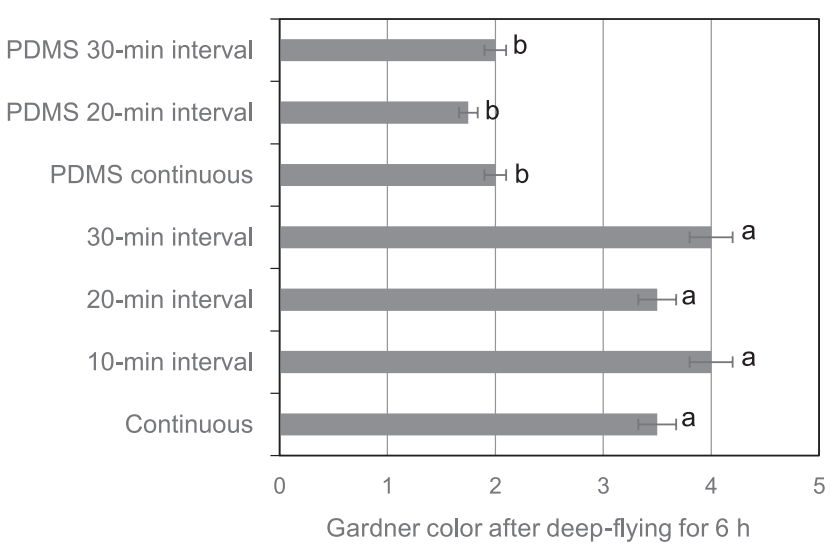

Fig. 3 Gardner color of canola oil with or without added PDMS used for deep-frying potato at 0 (continuous), 10-, 20-, or 30-min intervals for $6 \mathrm{~h}$. Values are expressed as mean \pm SD. Values with non-common superscript letters differ significantly $(p<0.05)$ by Dunnett's multiple comparison post hoc test. 
related more to the heating time rather than to the amount of potato fried. Oil with added PDMS showed significantly less color deterioration and again there was no statistical difference among the samples.

The concentration of PDMS (2 ppm at the start of deepfrying) could have changed as the deep-frying procedure proceeded because of the absorption by potato and the thermal decomposition of PDMS. However, this decrease was not determined because the quantification of PDMS is very difficult at concentrations below $5 \mathrm{ppm}^{11)}$.

\subsection{Effects of a continuous supply of water on oil with and without added PDMS}

The conditions used for this thermal treatment experiment resembled that of section 2.3 in terms of the ratio of water added to the oil heated for $6 \mathrm{~h}$; that is, the water ratio to oil was close to that of continuous deep-frying. Table 2 shows the SVR after 0 and $6 \mathrm{~h}$ of heating and the temperature range measured during heating.

The continuous supply of water during the first $3 \mathrm{~h}$ of heating canola oil without added PDMS had no effect on the measured values but the increase in PC was retarded after $5 \mathrm{~h}$ (Fig. 4) due to the steam distillation of decomposition products generated during heating, as shown in Fig. 2. When canola oil containing PDMS was heated, much lower increases in PC values were observed compared to canola oil not containing PDMS. The continuous supply of water to canola oil containing PDMS resulted in a gradual increase in PC after $2 \mathrm{~h}$ of heating, in contrast to the findings of Marquez-Ruiz et al. ${ }^{12-15)}$. PC values indicate the balance of the amount of oil-degradation compounds and that of steam-distilled during deep-frying, so that the amount of steam-distilled degradation compounds has a direct influence on the size of PC values. In our experiments the hydrolysis/ decomposition of oil exceeded the amount of product distilled out by steam because the PDMS particles reduced the evaporation of volatile oil-degradation compounds during deep-frying.

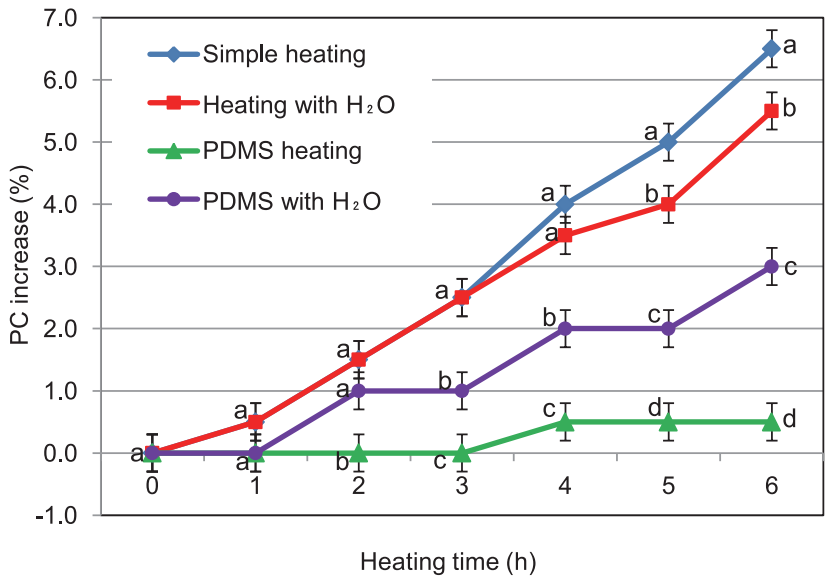

Fig. 4 Polar compound content of canola oil with or without added PDMS heated at $180^{\circ} \mathrm{C}$ for $6 \mathrm{~h}$ with and without a continuous water supply. Values are expressed as mean \pm SD. Values with non-common superscript letters differ significantly $(p<0.05)$ by Dunnett's multiple comparison post hoc test.

\subsection{Polymerization of oil in deep-frying operations}

The polymerization of canola oil was estimated by the increase in viscosity during deep-frying ${ }^{27)}$. The viscosity of canola oil without added PDMS increased by $20 \%$ in continuous and 10-min interval frying, by $40 \%$ in 20-min and 30 -min interval fryings. From this result it was proved that thermal oxidation proceeded vigorously during idle time of interval frying in canola oil without added PDMS. However, canola oil containing PDMS showed no detectable increase in viscosity (Fig. 5), indicating that thermal oxidation and polymerization via oxidized triacylglycerols was largely inhibited using the current deep-frying conditions ${ }^{31}$. When the interval frying was carried out in canola oil containing PDMS, PDMS layer over the surface of the oil inhibited oxygen penetration from air during idle time, and thermal oxidation hardly proceeded as well as polymerization.

Table 2 Thermal treatment of canola oil containing PDMS and water.

\begin{tabular}{lcccc}
\hline & $\begin{array}{c}\text { Simple } \\
\text { heating }\end{array}$ & $\begin{array}{c}\text { Heating with } \\
\text { water }\end{array}$ & $\begin{array}{c}\text { PDMS } \\
\text { heating }\end{array}$ & $\begin{array}{c}\text { PDMS } \\
\text { heating with } \\
\text { water }\end{array}$ \\
\hline SVR $\left(\mathrm{cm}^{-1}\right) 0 \mathrm{~h}$ & 0.199 & 0.199 & 0.199 & 0.199 \\
SVR $\left(\mathrm{cm}^{-1}\right) 6 \mathrm{~h}$ & $0.219 \pm 0.002^{\mathrm{b}}$ & $0.229 \pm 0.002^{\mathrm{a}}$ & $0.219 \pm 0.002^{\mathrm{b}}$ & $0.226 \pm 0.002^{\mathrm{a}}$ \\
The highest temperature $\left({ }^{\circ} \mathrm{C}\right)$ & 182 & 183 & 182 & 182 \\
The lowest temperature $\left({ }^{\circ} \mathrm{C}\right)$ & 175 & 166 & 174 & 162 \\
\hline
\end{tabular}

PDMS: polydimethylsiloxane, SVR: surface to volume ratio. Values of SVR $\left(\mathrm{cm}^{-1}\right) 6 \mathrm{~h}$ are expressed as mean $\pm \mathrm{SD}$. Values with non-common superscript letters differ significantly $(p$ $<0.05$ ) by Dunnett's multiple comparison post hoc test. 


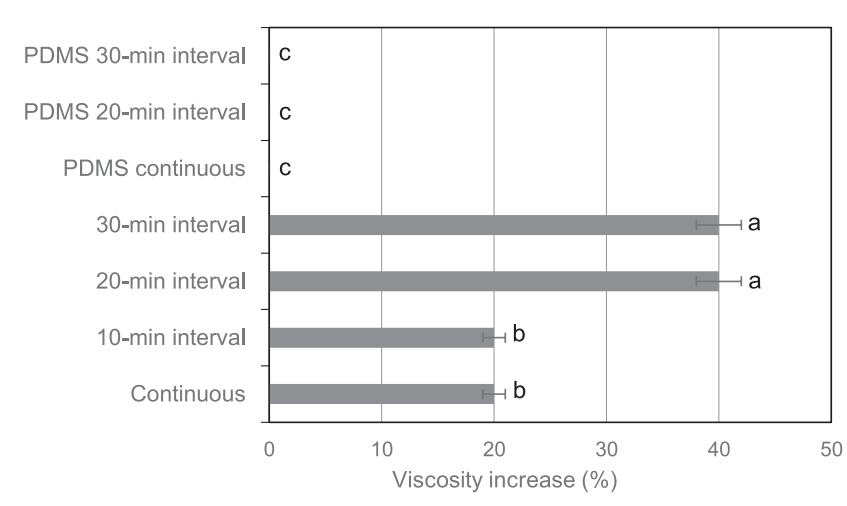

Fig. 5 Viscosity increase of canola oil with or without added PDMS used for deep-frying potato at 0 (continuous), 10-, 20-, or 30-min intervals for $6 \mathrm{~h}$. Values are expressed as mean \pm SD. Values with non-common superscript letters differ significantly $(p<0.05)$ by Dunnett's multiple comparison post hoc test.

\subsection{Correlation between PC determined using a tes- to $270^{\circledR}$ and by column chromatography}

The Japan Oil Chemists' Society standard method for determining the $\mathrm{PC}$ of oil requires equipment such as a glass column, a separatory funnel, silica gel 60, sea sand, and developing solvent (hexane/diethyl ether, 87:13 v/v). For column chromatography, oil is eluted using the developing solvent and solvent is removed from the eluent containing triacylglycerol using a rotary evaporator. The entire process takes about $3 \mathrm{~h}$. In addition, the triacylglycerol fraction must be kept at $2 \mathrm{kPa}$ overnight to completely remove the solvent. The $\mathrm{PC}$ value is calculated using the formula $(\mathrm{A}-\mathrm{B}) / \mathrm{A} * 100$, where $\mathrm{A}$ is the weight of oil sampled $(2.5 \pm 0.1 \mathrm{~g})$ and $\mathrm{B}$ is the weight of recovered oil (intact triacylglycerol). In the present study, PC values ranged 0-25\%, which are within allowable limits according to EU and US regulations ${ }^{32}$. Incomplete removal of solvent from the triacylglycerol fraction provides erroneously small PC values. Figure 6 shows that the PC values obtained using the testo2 $70^{\oplus}$ were larger than those obtained by chromatography.

These two methods typically provide somewhat different PC values because separation is achieved using different properties of the polar compounds. Testo $270^{\circledR}$ separation is based on the electrostatics of polar compounds, while the standard method is based on the low polarity of intact triacylglycerol. However, Fig. 6 shows that the value obtained using the testo $270^{\circledR}$ correlates linearly with that obtained by the standard method, indicating that values obtained using the former method are satisfactory for our investigation as long as we do not compare the values obtained by the two methods. We determined the PC values of oil in sections 2.3 and 2.4 exclusively using the testo $270^{\circledR}$.

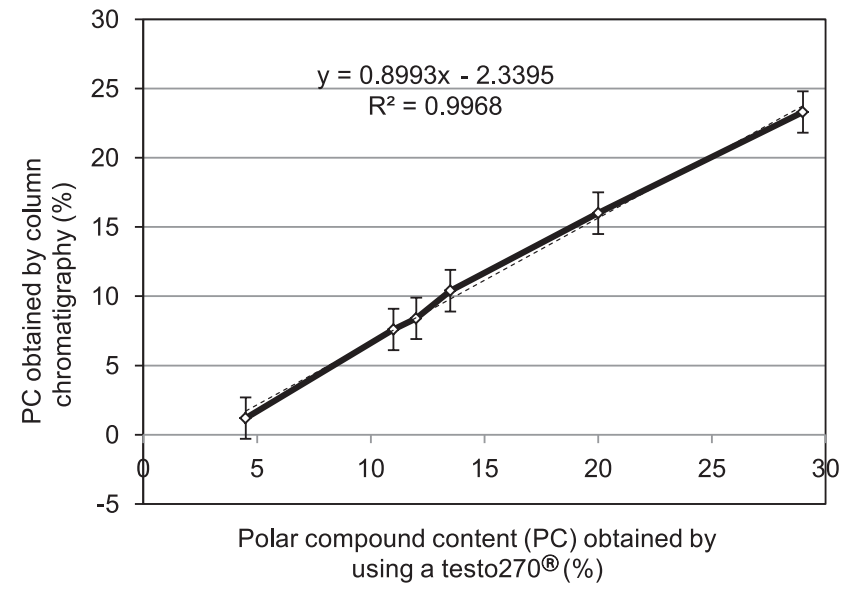

Fig. 6 Correlation between polar compound content obtained by column chromatography and using a testo $270^{\circledast}$. Values are expressed as mean \pm SD.

\section{Conclusion}

Canola oil with/without added PDMS was used to deepfry shredded potato at $180^{\circ} \mathrm{C}$ either continuously or with 10-, 20-, or 30-min intervals between frying sessions for $6 \mathrm{~h}$. In continuous deep-frying using canola oil without added PDMS, much more oil vapor was generated from the oil and water in the potato compared to when there were 20 and 30-min intervals between frying and the PC value of the oil was accordingly lower. In contrast, the addition of PDMS drastically decreased thermal deterioration and oil vaporization in both continuous and interval frying, and the slight increase in PC value was proportional to the amount of potato deep-fried. PDMS particles dispersed in canola oil have a high zeta potential and form a network in oil ${ }^{7}$, thus greatly inhibiting oil volatilization. We suggest that fewer polar compounds, such as decomposition products and hydrolyzed triacylglycerols, evaporated from oil containing PDMS compared to canola oil not containing PDMS.

In conclusion, we observed superior protective effects of PDMS regardless of the pattern of deep-frying and the PC value increased gradually according to the amount of food deep-fried.

\section{References}

1) Ohta, S. Deterioration inhibitors for frying oils. Yukagaku 37, 331-343 (1988).

2) Hamamoto, T.; Sugimoto, I. Deodorization and oxidation stability of edible oil. Nihon Yukagaku Kaishi 48, 1123-1131 (1999).

3) Usuki, R.; Kimura, T.; Kaneda, T. The effect of silicone oil on the thermal deterioration of frying oil. J. Jpn. Soc. Food Sci. Tech. 25, 338-341 (1978).

4) Warner, K.; Mounts, T.L.; Kwolek, W.F. Effects of antioxidants methyl silicone and hydrogenation on room 
odor of soybean cooking oils. J. Am. Oil Chem. Soc. 62, 1483-1486 (1985).

5) Freeman, I.P.; Padley, F.B.; Sheppard, W.L. Use of silicones in frying oils. J. Am. Oil Chem. Soc. 50, 101103(1973).

6) Yawata, M.; Iwahashi, M.; Hori, R.; Shiramasa, H.; Totani, N. The antioxidation mechanism of polydimethylsiloxane in oil. J. Oleo Sci. 64, 853-859(2015).

7) Totani, N.; Yazaki, N.; Yawata, M. Polydimethylsiloxane droplets exhibit extraordinarily high protective effects in deep-frying. J. Oleo Sci. 66, 329-336 (2017).

8) Gerde, J.A.; Hammond, E.G.; White, P.J. Influence of polydimethylsiloxane on the oxygen concentration of oils at various temperatures. J. Am. Oil Chem. Soc. 88, 925-929 (2011).

9) Gerde, J.A.; Hammond, E.G.; White, P.J. Influence of polydimethylsiloxane on the formation of 4-hydroxynonenal in soybean oil at frying temperature. $J$. Am. Oil Chem. Soc. 88, 1503-1510 (2011).

10) Gerde, J.A.; Hammond, E.G.; White, P.J. Influence of polydimethylsiloxane on the degradation of soybean oil at frying temperature. J. Am. Oil Chem. Soc. 88, 1573-1579 (2011).

11) Yawata, M.; Iwahashi, M.; Hori, R.; Shiramasa, H.; Totani, N. A Study on the effect of polydimethylsiloxane from the viewpoint of oxygen content in oil. J. Oleo Sci. 63, 987-994(2014).

12) Marquez-Ruiz, G.; Velasco, J.; Dobarganes, M.C. Effectiveness of dimethylpolysiloxane during deep frying. Eur. J. Sci. Technol. 106, 752-758(2004).

13) Jorge, N.; Marquez-Ruiz, G.; Martin-Polvillo, M.; RuizMendez, M.V.; Dobarganes, M.C. Influence of dimethylpolysiloxane addition to frying oils: performance of sunflower oil in discontinuous and continuous laboratory frying. Grasas y Aceites 47, 20-25 (1996).

14) Sebedio, J.L.; Dobarganes, C.; Marquez, G.; Wester, I.; Christie, W.W.; Dobson, G.; Zwobada, F.; Chardigny, J.M.; Mairot, Th.; Lahtinen, R. Industrial production of crisps and prefried French fries using sunflower oil. Grasas y Aceites 47, 5-13 (1996).

15) Niemela, J.R.K.; Wester, I.; Lahtinen, R.M. Industrial frying trials with high oleic sunflower oil. Grasas y Aceites 47, 1-2 (1996).

16) Rock, S.; Fisher, L.; Roth, H. Methyl silicone in frying fats - Antioxidants or prooxidants? J. Am. Oil Chem. Soc. 44, 102A (1967).

17） Kusaka, H.; Gamou, H.; Monda, S.; Shinbori, K.;Ohta, S.
On functions of silicone oil in frying oil. IV. Effects of silicone oil on the thermal deterioration of frying oil. $J$. Jpn. Oil Chem. Soc. 33, 843-849 (1984).

18) Tian, L.L.; White, P.J. Antipolymerization activity of oat extract in soybean and cottonseed oils under frying condition. J. Am. Oil Chem. Soc. 71, 1084-1094 (1994).

19) Totani, N.; Inoue, R.; Yawata, M. Inhibition of frying oil oxidation by carbon dioxide blanketing. J. Oleo Sci. 65, 517-523 (2016).

20) Aladedunye, F.A.; Przybyiski, R. Protecting oil during frying: A comparative study. Eur. J. Lipid Sci. 111, 893-901 (2009).

21) Totani, N.; Ono, M.; Munkjargal, B.; Ojiri, Y. Carbonyl compounds vaporize from oil with steam during deepfrying. J. Oleo Sci. 56, 449-456 (2007).

22) Totani, N.; Yawata, M.; Mori, T.; Hammond, E.G. Oxygen content and oxidation in frying oil. J. Oleo Sci. 62, 989-996 (2013).

23) Takasago, M.; Takaoka, K. Interaction of dissolved water and dissolved oxygen in methyl decanoate, decanoic acid and 1-decanol. Yukagaku 31, 91-97 (1982).

24) Takasago, M.; Takaoka, K.; Toyama, Y. Influence of water content on autoxidation of safflower oil. Yukagaku 29, 162-168(1980).

25) Endo, Y. Methods for determining deterioration of oils, fats and foods containing oils and fats. The report by Food Analysis Technology Center SUNATEC, www. mac.or.jp/mail/131101/02.shtml, 2017.5.19.

26) Hara, S. Quality control and effective utilization of natural oils and fats. Oleoscience 10, 453-460 (2010).

27) Fujimura, K.; Anada, T.; Shiramasa H.; Matoba, T. Comprehensive frying oil control method for business use of deep-fry cooking. Nippon Shokuhin Kagaku Kaishi 49, 422-427 (2002).

28) Kusaka, H.; Kiyama, T.; Saita, H.; Koike, S.; Ohta, S. Functions of silicone oil in frying oil. VI . Effects of silicone oil on water and dissolved gas content in frying oil. Yukagaku 35, 467-471 (1986).

29) Babayan, K. US Pat. 2,998,319(1961).

30) Niki, E. Vitamin $E$ and its related compounds as antioxidants. J. Synthetic Organic Chem. Jpn. 47, 902915(1989).

31) Totani, Y.; Hara, S. Yushi no Kagaku ISBN 978-4-25443552-8, Asakura Shoten, Tokyo, Japan (2015).

32) Firestone, D. Worldwide regulation of frying fats and oils. Inform 4, 1366-1371 (1993). 